\title{
Study of adverse drug reactions in a tertiary care teaching hospital
}

\author{
Ramya Ravichandar*, Jamuna Rani R., Sathyanarayanan Varadarajan
}

Department of Pharmacology, SRM Medical College Hospital and Research Centre, Potheri, Kattankulathur, Tamil Nadu, India

Received: 16 December 2015 Accepted: 07 January 2016

\section{*Correspondence to:}

Dr. Ramya Ravichandar, Email: dr.ramyaravichandar @gmail.com

Copyright: (C) the author(s), publisher and licensee Medip Academy. This is an openaccess article distributed under the terms of the Creative Commons Attribution NonCommercial License, which permits unrestricted noncommercial use, distribution, and reproduction in any medium, provided the original work is properly cited.

\begin{abstract}
Background: Adverse drug reactions (ADRs) are the recognized dangers of drug treatment and can arise with several groups of drugs. The purpose of this study was to identify and assess ADRs in inpatients of a tertiary care teaching hospital in Potheri.

Methods: A prospective spontaneous reporting was carried out in a tertiary care teaching hospital, Potheri for a period of eight months. The causality assessment of the reported ADRs was done using the Naranjo causality assessment scale. The severity of ADRs was classified as mild, moderate or severe according to the modified Hartwig and Siegel scale.

Results: A total of 62 ADRs were reported with male preponderance (51.6\%). Majority of ADRs was from General Medicine and General Surgical departments in which the most affected organ systems were the skin (69.4\%) and the gastrointestinal system (8.1\%). The most frequent drugs causing ADRs were antibiotics $(53.2 \%)$ in which type B reactions were more compared to type A. The severity assessment showed that most of them were mild reactions $(51.6 \%)$. Causality assessment revealed that $61.3 \%$ of the reactions were probable, possible $(30.6 \%)$, definite $(8.1 \%)$ and no reactions were unlikely.

Conclusions: The study accomplished that ADRs are widespread and a few of them raised the healthcare expenditure due to the increased hospital stay. The reporting of ADRs to regional pharmacovigilance centres should be encouraged to ensure drug safety.
\end{abstract}

Keywords: Adverse drug reactions, Drug safety, Pharmacovigilance

\section{INTRODUCTION}

An adverse drug reaction is 'a response to a drug that is noxious and unintended and which occurs in doses normally used for the treatment, prophylaxis, or diagnosis of disease, or the modification of physiological function' (World Health Organization). ${ }^{1}$ Adverse drug reactions affect patients' convalescence as well as the finances of health care. They are important causes of mortality and morbidity in both ambulatory and hospitalized patients. So there is a need to analyse ADRs to create awareness among patients and to motivate healthcare personnel to report ADRs. Early recognition, evaluation and monitoring of ADR are essential to improve public health.
In the United States, it has been reported that ADRs due to over the counter and prescription drugs from 1966 to 1996 affected $6.7 \%$ of patients with $3.2 \%$ death. ${ }^{2}$ While similar figures are not available for India, it is logical to assume that the figures would be much higher considering high levels of unmonitored and indiscriminate drug use widespread in the country. ${ }^{3}$ India is a developing country with a large drug utilising population. It is the fourth largest producer of pharmaceuticals in the world with more than 6000 licensed drug manufacturing firms and over 60,000 branded formulations. It is also emerging as a focus for clinical trials exposing larger population to newer drug treatments. It is critical to identify ADRs at the earliest and to prevent them if possible, to ensure the welfare of the patient at a reasonable expenditure. 
The Central Drugs Standard Control Organisation (CDSCO), New Delhi, under the guidance of Ministry of Health \& Family Welfare, Government of India has initiated a countrywide pharmacovigilance programme (PvPI) in 2010, with the All India Institute of Medical Sciences (AIIMS), New Delhi as the National Coordinating Centre for monitoring ADRs in the nation. Our hospital is one of the centres for monitoring and reporting ADRs through this programme.

\section{METHODS}

After obtaining approval of the Institutional Ethics Committee, a prospective spontaneous reporting study involving active methods (pharmacist actively seeking suspected ADRs) and passive methods (stimulating clinicians to report suspected ADRs) was carried out in all departments of a tertiary care teaching hospital, Potheri for a period of eight months. ${ }^{4}$ Patients of all age groups who developed Adverse Drug Reactions were included for the study. Informed consent was obtained from the patients. The data for the study were taken from case sheets, investigation reports, personal interviews with clinicians, and personal interviews with patient or patient's attendant, past history of medications and reports of Medical and surgical interventions.

The causality assessment of the reported ADRs was done using the Naranjo causality assessment scale into definite, probable, or possible. ${ }^{5}$ The modified Hartwig and Siegel scale defines the severity of ADR as mild, moderate or severe according to factors like necessities for change in treatment, length of hospital stay, and the disability produced by the ADR. ${ }^{6}$

\section{RESULTS}

During the study period, 62 adverse drug reactions were reported. Of these, $32(51.6 \%)$ were males and 30 $(48.3 \%)$ were females (Figure 1). The male to female ratio according to occurrence of ADRs was 1.06 . Pediatric patients (<18years) experienced $2 \quad(3.22 \%)$ ADRs, followed by geriatric patients (>60years) 12 (19.35\%) ADRs and adults 48 (77.42\%) ADRs (Figure 2). Classification of ADRs showed that most of the reactions were type $\mathrm{B}$ (Bizarre) reactions.

According to the Naranjo algorithm scale, 38 (61.3\%) reactions were assessed to be probable, $19(30.6 \%)$ as possible and $5(8.1 \%)$ as definite. Severity assessment of the ADRs showed that the majority of the reactions were mild $(32,51.6 \%)$, followed by moderate $(24,38.7 \%)$ and severe $(6,9.7 \%)$. In $56(90.3 \%)$ ADRs, complete recovery were achieved. Five $(8.1 \%)$ ADRs were classified as 'unknown outcomes' since the outcomes could not be assessed as the patients wanted voluntary discharge from the hospital. In $45(72.5 \%)$ patients, the offending drug was stopped. The offending drug was substituted with another drug in $2(3.2 \%)$ patients and the dose was reduced to alleviate the symptoms in $4(6.5 \%)$ patients. No change in treatment was endeavoured in 11 (17.7\%) patients. Causality assessment was done according to Naranjo et al. Outcomes were assessed according to Hartwig et al (Table 1).

Table 1: Classification and assessment of ADRs.

\begin{tabular}{|ll|}
\hline Parameter & Number of ADRs (\%) \\
\hline Causality & $5(8.1 \%)$ \\
\hline definite & $38(61.3 \%)$ \\
\hline probable & $19(30.6 \%)$ \\
\hline possible & \\
\hline Onset of ADRS & $4(6.5 \%)$ \\
\hline Acute(<1hr) & $37(59.6 \%)$ \\
\hline Sub-acute(1-24 hrs) & $21(33.9 \%)$ \\
\hline Latent(>2days) & \\
\hline Severity & $32(51.6 \%)$ \\
\hline mild & $24(38.7 \%)$ \\
\hline moderate & $6(9.7 \%)$ \\
\hline severe & \\
\hline Outcomes & $1(1.6 \%)$ \\
\hline fatal & $56(90.3 \%)$ \\
\hline fully recovered & $5(8.1 \%)$ \\
\hline unknown & \\
\hline Treatment & $45(72.5 \%)$ \\
\hline stopped the medication & $4(6.5 \%)$ \\
\hline reduced the dose & $2(3.2 \%)$ \\
\hline substituted another drug & $11(17.7 \%)$ \\
\hline no change & \\
\hline
\end{tabular}

Antibiotics were associated with about half of all the ADRs reported $(33,53.2 \%$ ) (Figure 3). Among the antibiotics, Ciprofloxacin was the most common drug to produce ADRs $(9,27.3 \%)$ followed by Cefotaxime (6, $18.2 \%$ ) (Table 3). Itching $(24,38.7 \%$ ) was the most common ADR reported followed by rashes (17, 27.4\%) and vomiting $(5,8.1 \%)$. The most commonly affected organ system was found to be the skin $(43,69.35 \%)$ followed by gastrointestinal and cardiovascular systems (5, 8.1\% each) (Table 2).

Table 2: Organ systems affected due to ADRs. The numbers represent the total number of ADRs that involved the corresponding organ system.

\begin{tabular}{|ll|}
\hline Organ system & Number of ADRs (\%) \\
\hline Skin & $43(69.4 \%)$ \\
\hline Gastrointestinal system & $5(8.1 \%)$ \\
\hline Cardiovascular system & $5(8.1 \%)$ \\
\hline Central nervous system & $4(6.5 \%)$ \\
\hline Respiratory & $2(3.2 \%)$ \\
\hline Genitourinary & $2(3.2 \%)$ \\
\hline Eyes, ears, nose and throat & $1(1.6 \%)$ \\
\hline
\end{tabular}


Table 3: ADRs associated with antibiotics.

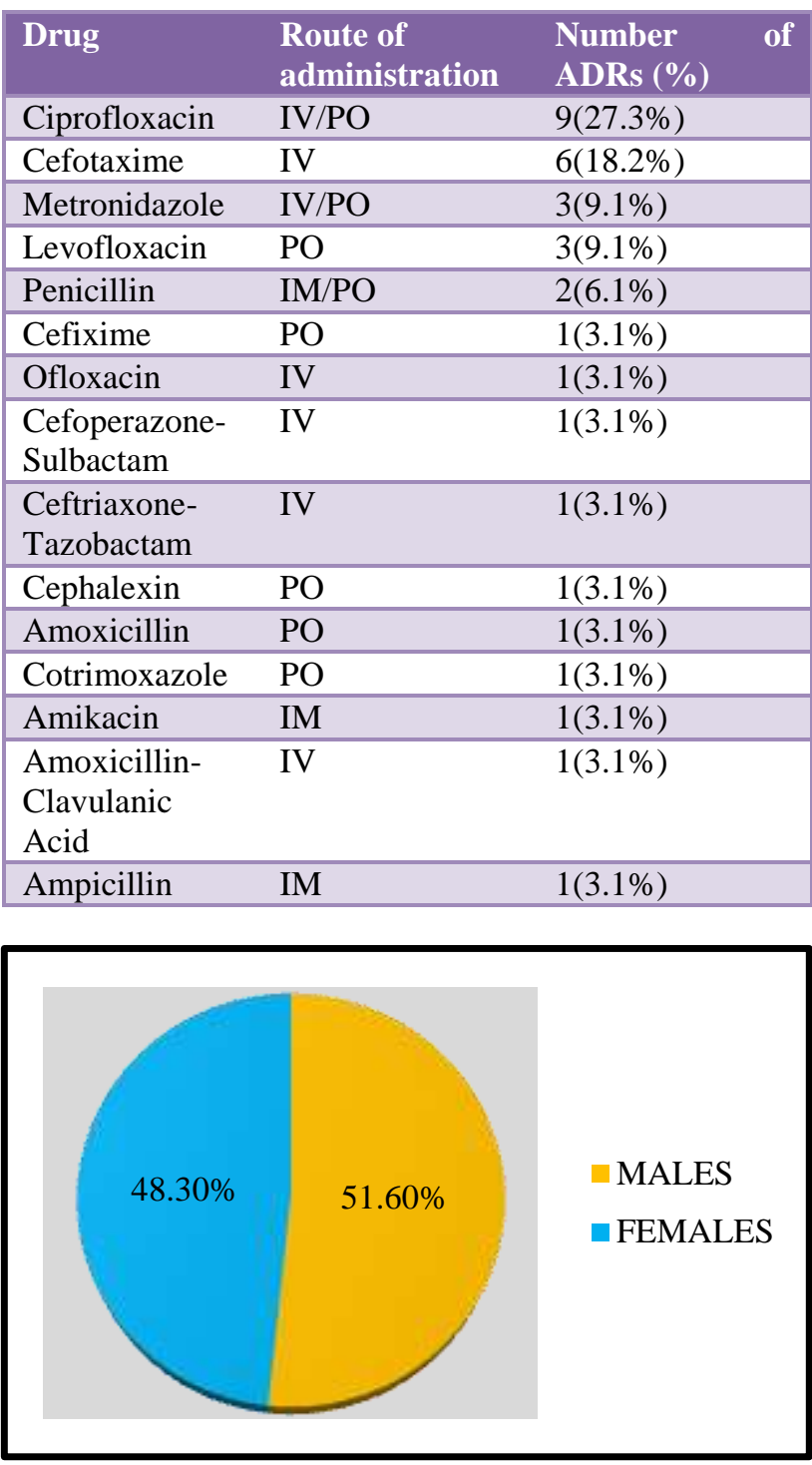

Figure 1: Division of ADRs based on the gender of the patients.

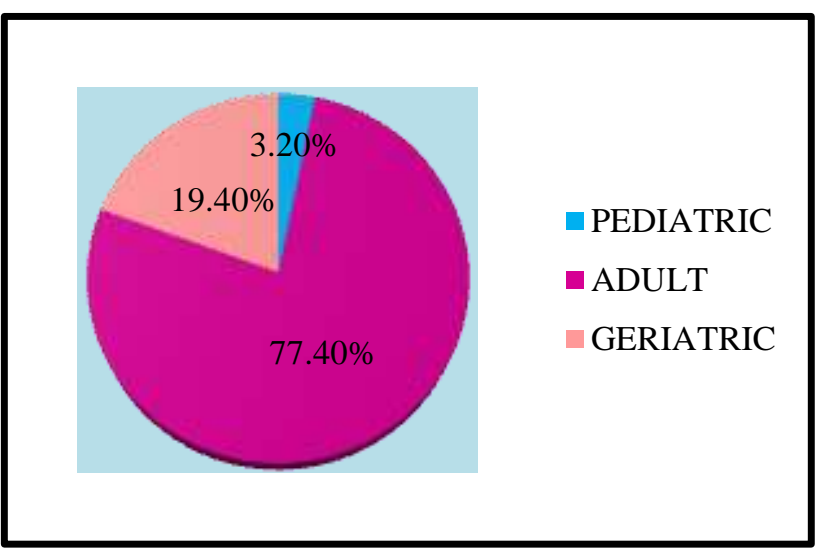

Figure 2: Distribution of ADRs based on age group of patients.

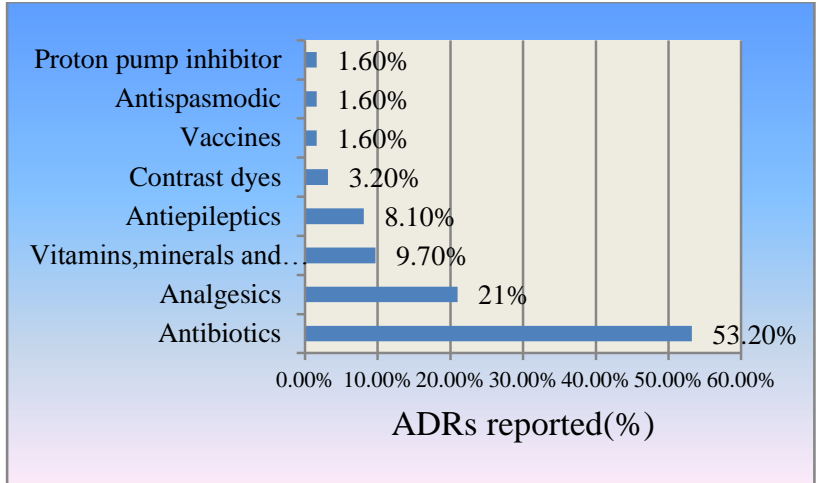

Figure 3: Most commonly involved groups of drugs in ADRs. The total number of reactions reported for each group is presented.

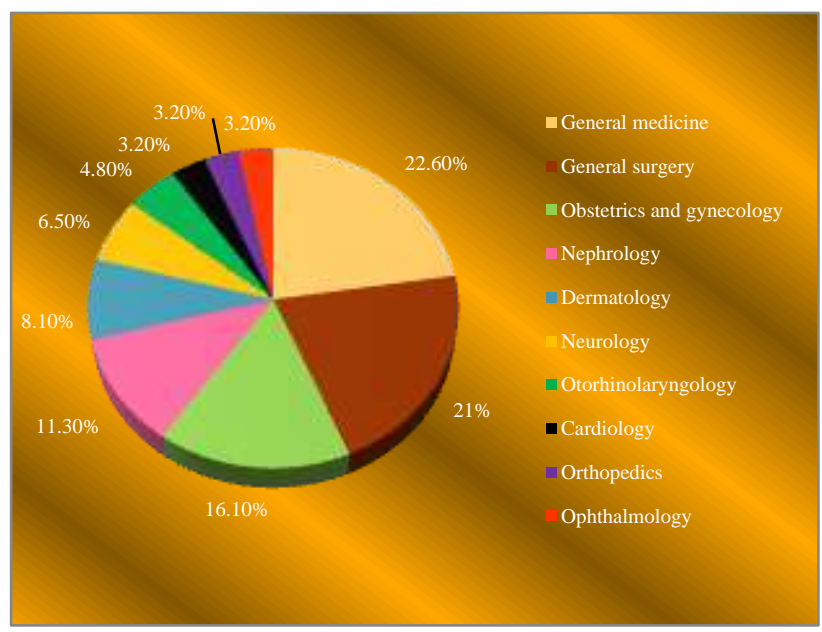

Figure 4: Number of ADRs received from different departments.

\section{DISCUSSION}

Majority of ADRs (77.4\%) were seen in adult age group which was comparable with the previous study by Sharma et al. where it was $50.4 \%$. ${ }^{7}$ The most frequent ADRs were due to the antibiotics which could be associated with increased frequency of prescription of antibiotics. The number of ADRs were high in General Medicine and General Surgery departments due to amplified use of antibiotics in these departments for the treatment and prophylaxis of various diseases and also since the patients admitted were with multiple comorbidities requiring polypharmacy. In accordance with previous studies by Misbah $\mathrm{M}$ et al, Oshikoya et al and Shareef et al, the present study showed the predominance of cutaneous manifestations. ${ }^{8-10}$ Classification of reported ADRs according to Rawlin and Thompson scale revealed Type B predominance. This result is in line with the study by Suthar and Desai but on the contrary, studies conducted by Oshikoya et al. and Stavreva et al. showed a preponderance of Type A reactions..$^{9,11,12}$ On analysing the fate of the suspected drugs, it was found that the drug was withdrawn in most of the cases and the dose was 
reduced in some while no change was made in others considering the risk benefit ratio in particular patients. Majority of the patients recovered completely from the ADR since most of the reactions were mild according to the modified Hartwig and Siegel scale. However, the study carried out by Shamna et al. reported that moderate reactions were more followed by mild and severe ones. ${ }^{4}$ Only one ADR was fatal which was not preventable. The causality assessment of the reported ADRs according to the Naranjo scale revealed that no reactions were unlikely and most of them were probable with a lesser number of possible and definite ADRs. This data is in correlation with the study of Jimmy Jose et al. ${ }^{12}$

\section{CONCLUSION}

The results of this study provide awareness to the healthcare providers on the significance of monitoring and reporting adverse drug reactions. The study accomplished that ADRs are widespread and a few of them raised the healthcare expenditure due to the increased hospital stay. The reporting of ADRs to regional pharmacovigilance centres should be encouraged to ensure drug safety.

\section{Funding: No funding sources}

Conflict of interest: None declared

Ethical approval: The study was approved by the Institutional Ethics Committee

\section{REFERENCES}

1. WHO. Safety of medicines - A guide to detecting and reporting adverse drug reactions - Why health professionals need to take actions, 2002. Available at:

http://apps.who.int/medicinedocs/en/d/Jh2992e/6.ht ml. Accessed on 03.10.2015.

2. Lazarou J, Pomeranz BH, Corey PN. Incidence of adverse drug reactions in hospitalized patients: a meta-analysis of prospective studies. JAMA. 1998;279(15):1200-5.

3. Sriram S, Ghasemi A, Ramasamy R, Devi M, Balasubramanian R, Ravi TK. Prevalence of adverse drug reactions at a private tertiary care hospital in south India. Journal of Research in Medical
Sciences: The Official Journal of Isfahan University of Medical Sciences. 2011;16(1):16-25.

4. Shamna M, Dilip C, Ajmal M, Linu Mohan P, Shinu C, Jafer CP. A prospective study on Adverse Drug Reactions of antibiotics in a tertiary care hospital. Saudi Pharmaceutical Journal: SPJ. 2014;22(4):3038 .

5. Naranjo CA, Busto U, Sellers EM, Sandor P, Ruiz I, Roberts EA. Method for estimating the probability of adverse drug reactions. Clin Pharmacol Ther. 1981;80:289-95.

6. Hartwig SC, Siegel J, Schneider PJ. Preventability and severity assessment in reporting adverse drug reactions. Am J Hosp Pharm. 1992;49:2229-32.

7. Sharma VK, Sethuraman G, Kumar B. Cutaneous adverse drug reactions: Clinical pattern and causative agents - a 6 year series from Chandigarh, India. J Postgrad Med. 2001;47(2):95-9.

8. Misbah Hussain M, Girhepunje K, Pal R, Sugra Siddiqua S. Incidence of adverse drug reactions in a tertiary care hospital: a systematic review and metaanalysis of prospective studies. Der Pharmacia Lettre. 2010;2(3):358-68.

9. Oshikoya KA, Njokanma OF, Chukwara HA, Ojo IO. Adverse drug reactions in Nigerian children. Paediatr. Perinat. Drug Ther. 2007;8:81-8.

10. Shareef SM, Naidu CDM, Raikar SR, Rao YV, Devika U. Development, implementation, and analysis of adverse drug reaction monitoring system in a rural tertiary care teaching hospital in Narketpally, Telangana. Int J Basic Clin Pharmacol. 2015;4(4):757-60.

11. Suthar JV, Desai SV. A study of adverse cutaneous drug reactions in outdoor patients attending to skin \& V.D. Department of Shree Krishna Hospital, Karamsad. Int $\mathrm{J}$ Res Pharm Biomed Sci. 2011;2(1):274-9.

12. Stavreva G, Pendicheva D, Pandurska A, Marev R. Detection of adverse drug reactions to antimicrobial drugs in hospitalized patients. Trakia J Sci. 2008;6(1):7-9.

13. Jose J, Rao Padma GM, Jimmy B. Adverse drug reactions to fluoroquinolone antibiotics - analysis of reports received in a tertiary care hospital. Int J Risk Saf Med. 2008;20:169-80.

Cite this article as: Ramya R, Jamuna Rani R, Varadarajan S. Study of adverse drug reactions in a tertiary care teaching hospital. Int J Basic Clin Pharmacol 2016;5:209-12. 